\title{
High Efficiency Squirrel Cage Induction Machines
}

\author{
T. Tudorache, L. Melcescu and V. Petre \\ ${ }^{1}$ Electrical Engineering Faculty, Electrical Machines, Materials and Drives Dept., \\ University POLITEHNICA of Bucharest \\ 313 Splaiul Independentei, 060042, Sect. 6, Bucharest (Romania) \\ Phone/Fax number: +0040 21 3197969, e-mail: tudorach@amotion.pub.ro, leonard@amotion.pub.ro, \\ petrevasileupb@gmail.com
}

\begin{abstract}
This paper highlights the benefits of replacing the classical cast aluminum cage with a cast copper cage in the manufacture of future generation of high efficiency induction machines used as motors or generators.

The numerical analysis carried out in the paper is based on a 2D plane-parallel finite element approach of the induction machine, the numerical results being discussed and compared with experimental measurements.
\end{abstract}

\section{Key words}

Induction machines, energy savings, FEM.

\section{Introduction}

The increasing global demand of energy corroborated with the continuous reduction of the limited resources of fossil fuel, determined the mankind to reevaluate the medium and long term energy strategies and policies.

A first adopted measure consists in accelerated exploration and development of new electrical energy production technologies based on renewable sources, such as wind energy, solar energy, etc.

Another adopted measure aimed to prevent a global energy crisis in the future supposes the encouragement of energy consumption cutback in both industrial and domestic areas. This measure is supported and imposed by a series of international and European norms, standards and protocols referring to high efficiency equipment, energy savings and energy recover techniques, cogeneration technologies etc.

A noteworthy example is the US radical directive that has been elaborated in 1992 and adopted in 1997 that interdicts the import of low voltage electric motors with efficiencies smaller than certain imposed values. A similar directive was adopted in Canada even earlier, in 1995. These regulations can be found in EPAct (The Energy Policy Act) and oblige the manufacturers of electric motors to explicitly inscribe the efficiency on the delivered motors and to validate them by certified laboratories accredited by EPAct.

As a replica to the US position, the International Electrotechnical Commission (IEC) decided in 2007 to propose a standard referring to the energy efficiency classes for electric motors [1]. By this standard IEC intends to keep only the old Eff2 (IE1) and Eff1 (IE2) classes (to give up the old energy efficiency class Eff3) and to add another two classes with even higher efficiencies, i.e. Premium Efficiency (IE3) and Super Premium Efficiency (IE4).

The replacement of poor efficiency electric motors with Eff1 or even higher efficiency class machines could entail important energy savings (up to more than $2 \%$ of the total electric energy consumed worldwide) and significant reduction of greenhouse gas emissions [1]-[2].

\section{High energy efficiency induction machines}

From the variety of electric energy consumers in industry one of the largest is without any doubt the induction machine operating as motor. Besides the classical destination of the induction machine as motor this machine is more and more used in the latest period as generator in the conversion chain of wind or micro-hydro energy into electricity. The induction generator is increasingly preferred in case of renewable energy systems due to its advantages over the synchronous generator, such as: reduced unit cost and size, ruggedness, brushless, absence of separate d.c. source, 
ease of maintenance, capacity of producing energy at variable speeds etc. [3].

Considering the extended use of induction machine in industrial or domestic applications both as motor and generator, the improvement of the energy efficiency of this energy converter represents a topic of high interest and could be a step forward in the context of the actual trend of energy efficiency and energy savings policy.

As a measure for increasing the induction machine energy efficiency, this paper proves that by simply replacing the cast aluminum rotor cage with cast copper cage [4-5], (recent developed technology), a higher energy efficiency machine could result, with a higher output power. Reversely, for a given rated power, the copper squirrel cage induction machine compared to the classical one (aluminum based) will have smaller overall size, essential feature for certain industrial applications such as transportation systems, wind turbines etc. In spite of the ease of replacement option, a redesign of the cast copper cage motor is a better solution leading to enhanced features and smaller costs [4].

\section{FEM model of the induction machine}

The physical support for this study is represented by an S1 duty class squirrel cage induction machine, manufactured by UMEB SA, Bucharest, Romania, that is characterized by the main data: rated power $2.2 \mathrm{~kW}$, rated voltage $230 / 400 \mathrm{~V}$, star connected windings, 4 poles, 36 stator slots and 28 rotor bars, lamination stack length $90 \mathrm{~mm}$, airgap thickness $0.5 \mathrm{~mm}$.

Taking into account all the specific physical symmetries, the 2D plane-parallel electromagnetic field computation domain is reduced to $1 / 4$ of the cross-section of the induction machine (one pole), Fig. 1.

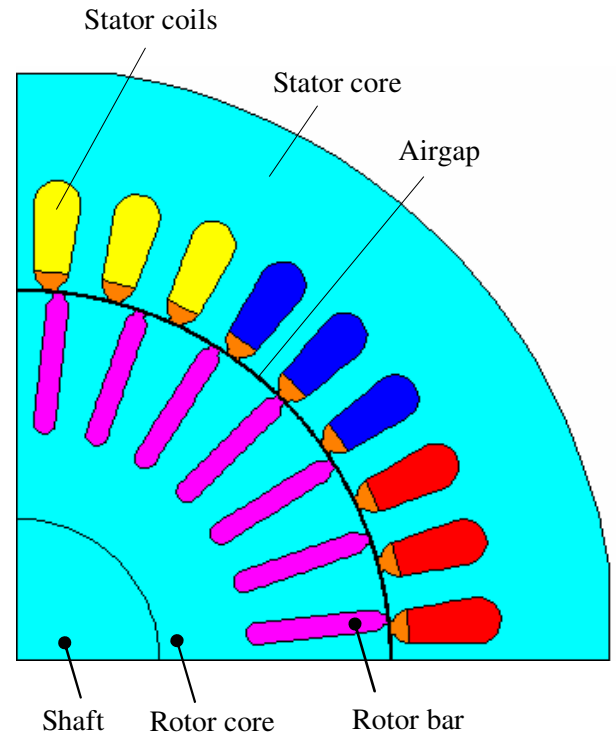

Fig. 1. Electromagnetic field computation domain and regions with different physical properties.
The stator and rotor magnetic cores, made of laminations, are nonlinear with a saturation flux density of $\mathrm{Bs}=2 \mathrm{~T}$. The insulation materials of the machine windings corespond to the $\mathrm{F}$ thermal class $\left(155^{\circ} \mathrm{C}\right)$. The electric resistivity of the aluminum cage is $5.07 .10-8 \Omega \mathrm{m}$ and the electric resistivity of copper cage is $2.4 .10-8 \Omega \mathrm{m}$ both corresponding to an average temperature of $115^{\circ} \mathrm{C}$.

The finite element discretization of the electromagnetic field computation domain, Fig. 2, includes 7820 second order elements of triangle shape with smaller size towards the air-gap where the most part of the magnetic energy of the machine is concentrated.

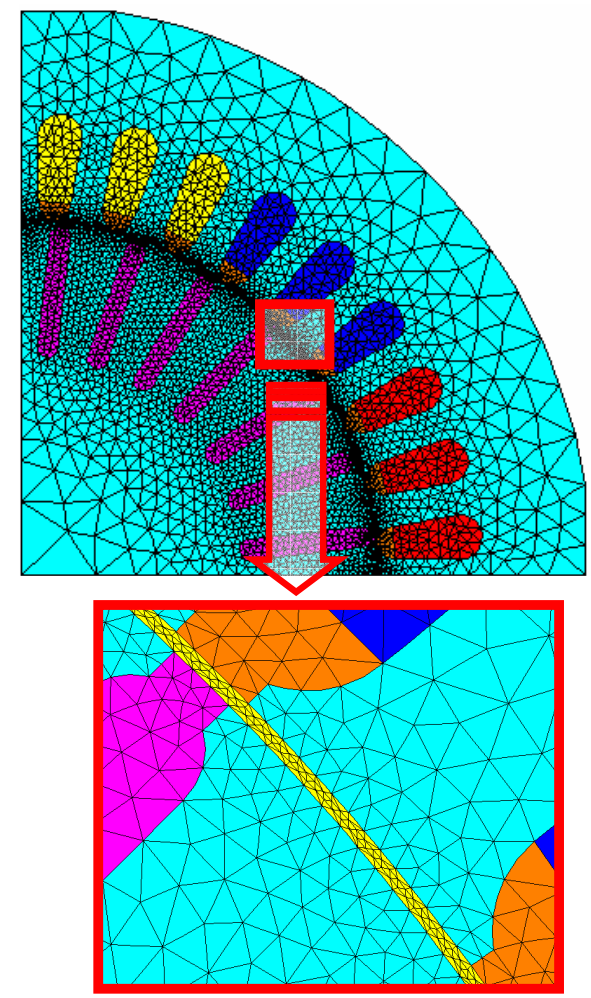

Fig. 2. Finite element discretization of computation domain (detail in the airgap region).

The 2D electromagnetic field computation model of the studied machines in $(\mathrm{x}, \mathrm{y})$ cartesian coordinates is based on the magnetic vector potential formulation characterized by the partial differential equation:

$$
\operatorname{curl}[(1 / \mu) \operatorname{curl} \mathbf{A}]=\mathbf{J}_{\mathbf{s}}-\mathbf{j} \sigma \omega \mathbf{A}
$$

where $\mathrm{A}[0,0, \mathrm{~A}(\mathrm{x}, \mathrm{y})]$ is the magnetic vector potential, $\mathrm{Js}[0,0, \mathrm{Js}(\mathrm{x}, \mathrm{y})]$ is the current density in the stator slots (apriori unknown), $\mu$ is the magnetic permeability and $\sigma$ is the electric conductivity. Since the studied induction machine is not current supplied the two unknown quantities A and Js in (1) are determined by coupling the finite element model of the machine, Fig. 1, with the corresponding circuit model, Fig. 3.

The circuit components presented in Fig. 3 are as follows: 


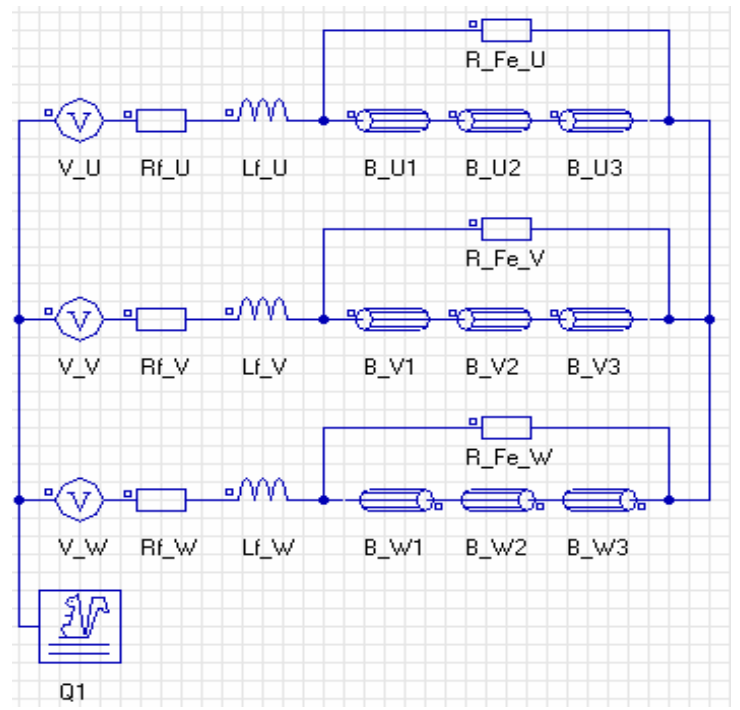

Fig. 3. Circuit model of the squirrel cage induction machine.

$-V_{-} U_{1} V_{-}$V and V_W are the voltage sources supplying the machine;

- Rf_U, Rf_V and Rf_W represent the stator resistance per phase;

- Lf_U, Lf_V and Lf_W symbolize the stator end winding inductance per phase;

- R_Fe_U, R_Fe_V and R_Fe_W signify the phase resistance modeling the machine iron losses;

- B_U1, B_U2, B_U3, B_V1, B_V2, B_V3, B_W1, B_W2, B_W3 represent the coils of the three-phase winding of the machine;

- Q1 is a macro-circuit (a feature of Flux software package) used to model the squirrel cage of the machine, Fig. 4; this is a closed circuit consisting of rotor bars (bar $\mathrm{k})$, resistances $\left(\mathrm{R}_{\mathrm{ik}}\right)$ and leakage inductances $\left(\mathrm{L}_{\sigma \mathrm{\sigma ik}}\right)$ corresponding to the inter-bar regions of the short-circuit rings (arcs between two adjacent bars), Fig. 4.

The resistances $\mathrm{R}_{\mathrm{rk}}$ and inductances $\mathrm{L}_{\sigma \mathrm{rk}}$ of the inter-bar regions of the end rings were computed using analytical formulas [6].

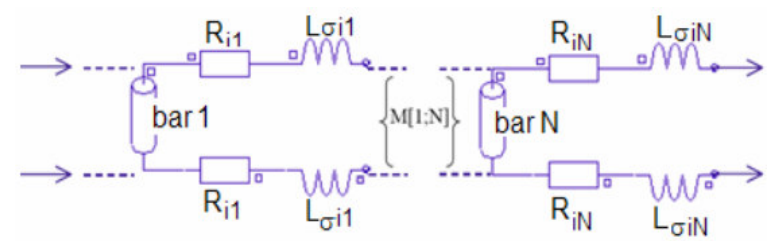

Fig. 4. Equivalent circuit of rotor cage.

\section{Energy efficiency computation}

The energy efficiency of the machine is computed by the ratio between the active output power $\mathrm{P}_{2}$ and the active input power $\mathrm{P}_{1}$ :

$$
\eta=\frac{P_{2}}{P_{1}}
$$

\section{A. Energy efficiency of induction motor}

The power balance of the induction motor includes the following quantities: $\mathrm{P}_{\mathrm{Fe}}$ - iron losses, $\mathrm{P}_{\mathrm{J} 1}$ - Joule losses in the stator windings, $\mathrm{P}_{\mathrm{J} 2}$ - Joule losses in the rotor cage, $\mathrm{P}_{\mathrm{m}, \mathrm{v}}$ - mechanical and ventilation losses, $\mathrm{P}_{\mathrm{e}}$ electromagnetic power at the airgap level, $\mathrm{P}_{\mathrm{s}}$ supplementary losses.

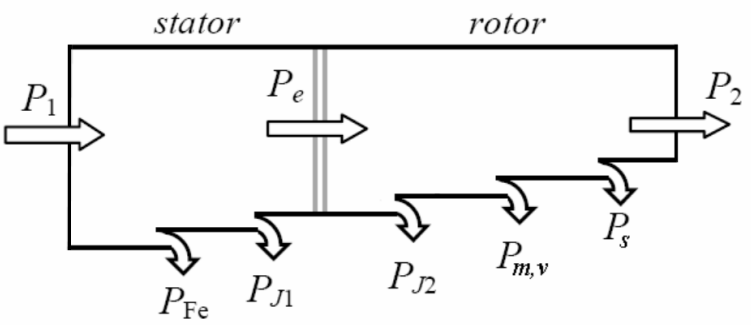

Fig. 5. Power balance of the induction motor.

The time varying stator magnetic flux produces iron losses in the stator magnetic core by eddy currents and hysteresis. The iron losses depend strongly on the frequency. Since the frequency of the rotor quantities $\left(f_{2}\right)$ depending on the machine slip (s) by the formula:

$$
\mathrm{f}_{2}=\mathrm{f}_{1} \cdot \mathrm{s}
$$

is much smaller than the frequency of the stator quantities $\left(f_{1}\right)$, the iron losses in the rotor core can be neglected.

The electric active power $\mathrm{P}_{1}$ absorbed by the induction motor is computed from the FEM model of the machine by using the expression:

$$
\left.P_{I}=\sum_{k=1}^{3} \Re e \underline{U_{k}}, \underline{I_{k}^{*}}\right\}
$$

where $\underline{U_{k}}$ represent the complex values of the voltage sources and $\underline{I}_{k}^{*}$ represents the complex conjugated values of the current through the voltage sources, Fig. 3.

The stator Joule losses are computed by the expression:

$$
P_{\mathrm{J} 1}=3 R_{\mathrm{s}} I_{\mathrm{s}}^{2}
$$

where $R_{s}$ is the stator phase resistance and $I_{s}$ is the stator phase current.

The electromagnetic power delivered to the rotor can be expressed by the formula:

$$
P_{\mathrm{e}}=M_{\mathrm{e}} \cdot \Omega_{1},
$$

where $M_{e}$ is the electromagnetic torque computed from the FEM model of the machine and $\Omega_{l}$ represents the synchronous angular speed of the machine computed by:

$$
\Omega_{l}=\frac{2 \cdot \pi \cdot n_{1}}{60},
$$


where $\mathrm{n}_{1}$ is the synchronous speed of the machine expressed in $\mathrm{rot} / \mathrm{min}$.

The rotor Joule losses $\mathrm{P}_{\mathrm{J} 2}$ are computed from the FEM model of the machine as the sum of the losses in the rotor bars and in the end rings:

$$
P_{\mathrm{J} 2}=P_{\text {bars }}+P_{\text {rings }}
$$

The active power dissipated in the rotor bars $\mathrm{P}_{\text {bars }}$ is computed by integrating the volume density of Joule losses $\mathrm{p}_{\mathrm{bars}}$ in the rotor bar regions (of volume $\mathrm{V}$ ) of the FEM model, and the active power $\mathrm{P}_{\text {rings }}$ dissipated in the end rings is computed by summing up the Joule losses in all the inter-bar regions (arcs situated between two adjacent bars)

$$
\begin{gathered}
P_{\text {bars }}=\int_{v} p_{\text {bars }} d V \\
P_{\text {rings }}=2 \cdot \sum_{k=1}^{Z_{2}} R_{i k} \cdot I_{i k}^{2}
\end{gathered}
$$

The rotor Joule losses can be computed as well by another expression (as a confirmation method):

$$
P_{\mathrm{J} 2}=\mathrm{s} \cdot P_{\mathrm{e}}
$$

The mechanical and ventilation losses $\mathrm{P}_{\mathrm{m}, \mathrm{v}}$ and the iron losses $\mathrm{P}_{\mathrm{Fe}}$ are taken from the technical specifications sheet of the studied machine. Based on the iron losses $\mathrm{P}_{\mathrm{Fe}}$ we compute the resistances $\mathrm{R} \_F e+U, \quad \mathrm{R} \_F e \_V$ and R_Fe_W used in the circuit model of the machine, Fig. 3. The supplementary losses are taken as $0.5 \%$ from the active power $P_{1}$ absorbed by the motor (according to IEC 60034-2-1 standard [7]):

$$
P_{\mathrm{s}}=0.5 \% \cdot P_{1}
$$

The output power $\mathrm{P}_{2}$ of the induction motor is computed using the following formula:

$$
P_{2}=P_{e}-P_{J 2}-P_{m, v}-P_{s}
$$

\section{B. Energy efficiency of induction generator}

In case of induction machine working as generator, the stator quantities in the power balance diagram, Fig. 6, are indexed with $2\left(\mathrm{P}_{2}, \mathrm{P}_{\mathrm{J} 2}\right)$ and the rotor quantities are indexed with $1\left(\mathrm{P}_{1}, \mathrm{P}_{\mathrm{J} 1}\right)$.

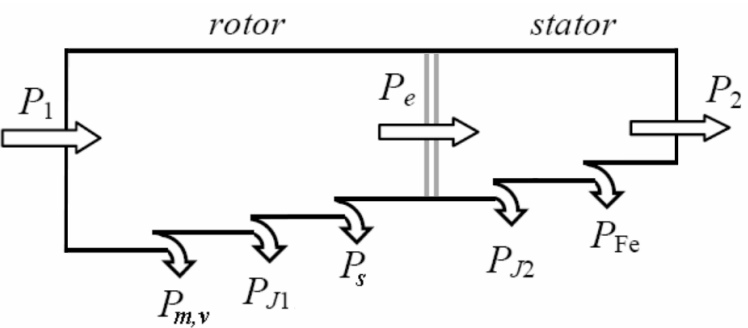

Fig. 6. Power balance of the induction generator.
The electrical active power $\mathrm{P}_{2}$ delivered by the induction generator to the grid is computed from the FEM model of the machine by using (4). The stator Joule losses $\mathrm{P}_{\mathrm{J} 2}$ are computed by (5). The rotor Joule losses $\mathrm{P}_{\mathrm{J} 1}$ are computed using (8)-(10). The mechanical power absorbed by the induction generator $\mathrm{P}_{1}$ is computed by the formula:

$$
P_{1}=P_{m, v}+P_{J l}+P_{s}+P_{e}
$$

The electromagnetic power $\mathrm{P}_{\mathrm{e}}$ is computed by the formula:

$$
P_{e}=P_{J 2}+P_{F e}+P_{2}
$$

\section{Numerical results for aluminum and copper squirrel cage induction machines}

By solving the 2D magneto- harmonic field problem using the Flux professional software package, we obtain the magnetic field lines and the chart of the magnetic flux density on the computation domain, Figs. 7 - 8 .

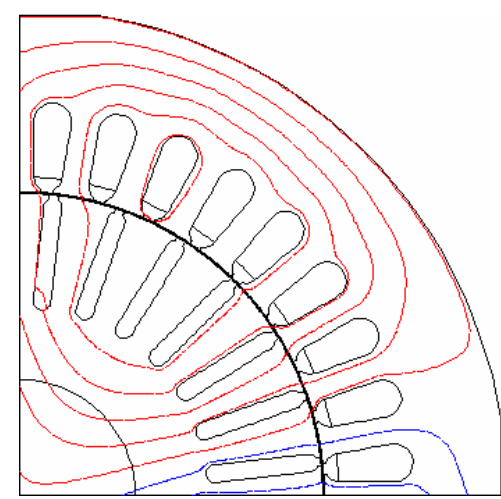

Fig. 7. Magnetic field lines on the FEM computation domain (rated load, aluminum cage).
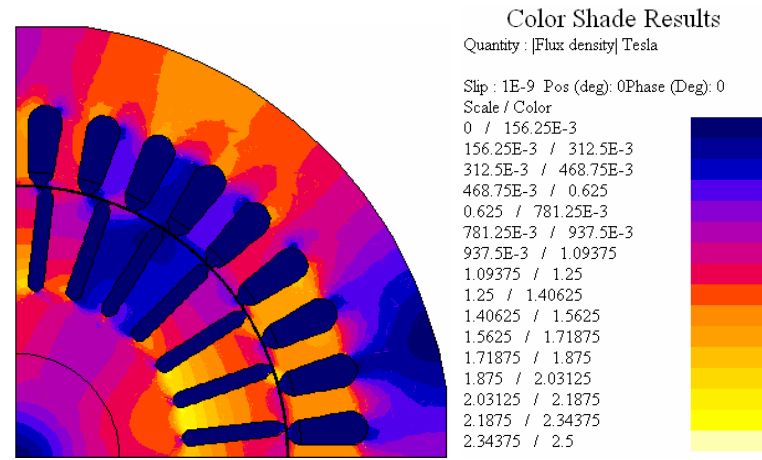

Fig. 8. Magnetic flux density chart on the FEM computation domain (rated load, aluminum cage).

By successive numerical simulations for different slip values in the range $[-1,1]$ we obtain the torque - slip characteristics of the induction machine equipped with aluminum or copper cage, working as motor or as generator, Figs. 9 - 10. 


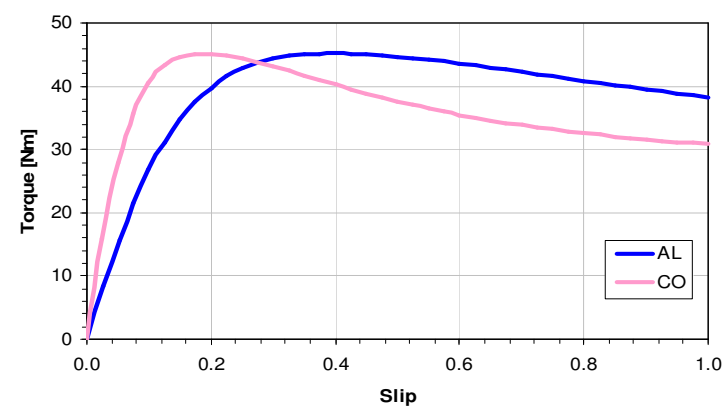

Fig. 9. Torque-slip curve of the induction motor for aluminum and copper cages.

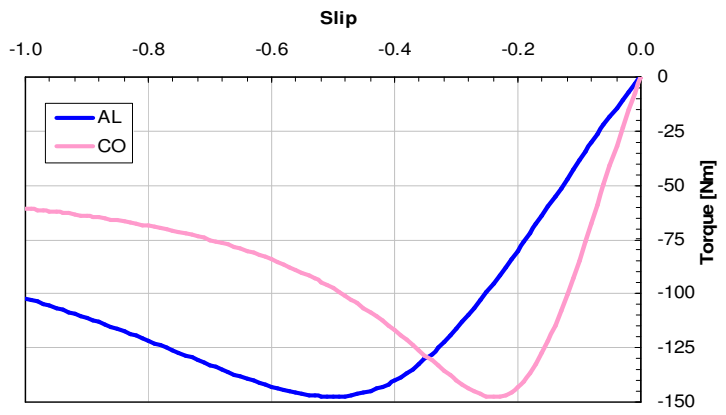

Fig. 10. Torque-slip curve of the induction generator for aluminum and copper cages.

Based on the previously described formulas applied for different slip values (by successive FEM simulations) we computed the curve "efficiency versus per unit load" for induction motor equipped with aluminum and copper squirrel cage, Fig. 11.

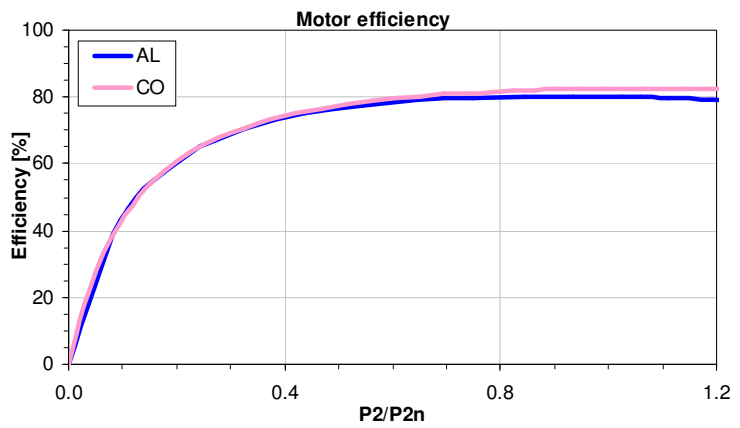

Fig. 11. Efficiency versus per unit load curve of the induction motor.

In case of induction machine equipped with aluminum and copper squirrel cage, working as generator, the curve "efficiency versus per unit load" obtained by FEM computations is presented in Fig. 12.

The numerical results, Figs. $9-12$, prove that for the rated point the energy efficiency of copper cage induction machine compared to the aluminum cage machine is $2.3 \%$ higher as motor and $1.8 \%$ higher as generator. The positive effect of replacing aluminum with copper on the machine energy efficiency was expected due to a much smaller electrical resistivity of copper compared to aluminum.

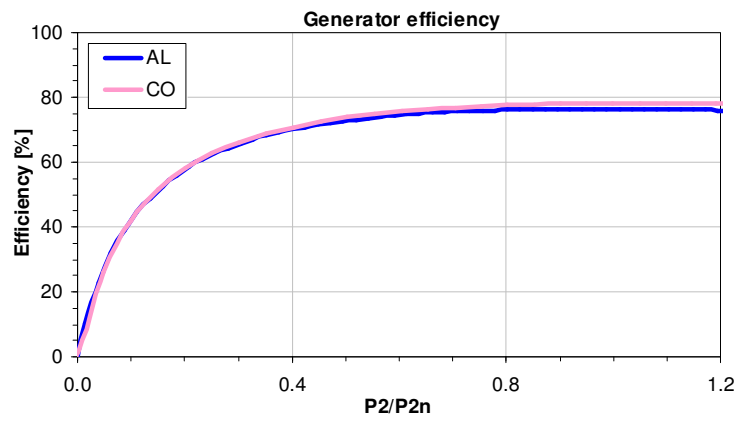

Fig. 12. Efficiency versus per unit load curve of the induction generator.

A disadvantage of copper cage induction motor consists however in a smaller starting torque with roughly $20 \%$ with respect to the aluminum cage machine, as we can see in Fig. 9. This disadvantage can be reduced nevertheless by a proper redesign of the copper cage machine.

\section{Numerical results for redesigned copper cage induction machine}

A higher starting torque of the induction motor with copper cage can be obtained by reshaping the rotor slots as in Fig. 13, where a double cage structure was used.

This solution leads to a significant improvement of the starting torque of the copper cage induction motor that becomes practically identical with the starting torque of the aluminum cage motor, Fig. 14.

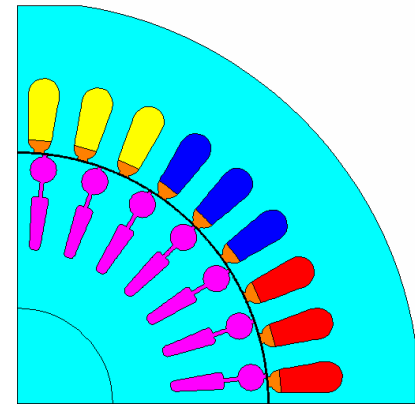

Fig. 13. New rotor slots shape used for improving the staring torque of copper cage induction motor.

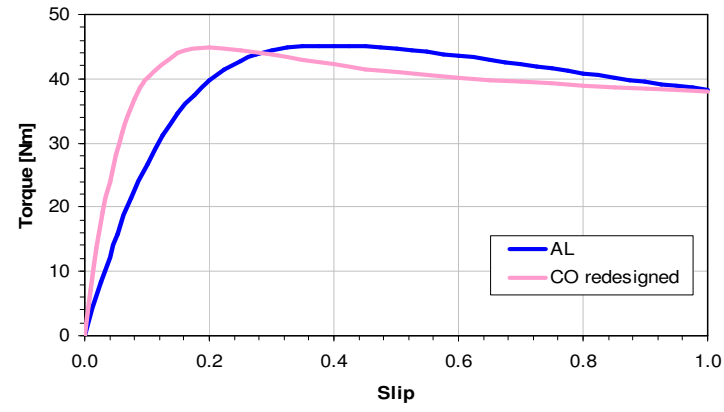

Fig. 14. Torque-slip curve of the induction motor for aluminum cage and for redesigned copper cage. 
The energy efficiency of the redesigned induction motor is $82.8 \%$, i.e. higher than that of the aluminum cage motor $(80.15 \%)$ and higher also than the previous copper cage motor (82.4\%), Fig. 15.

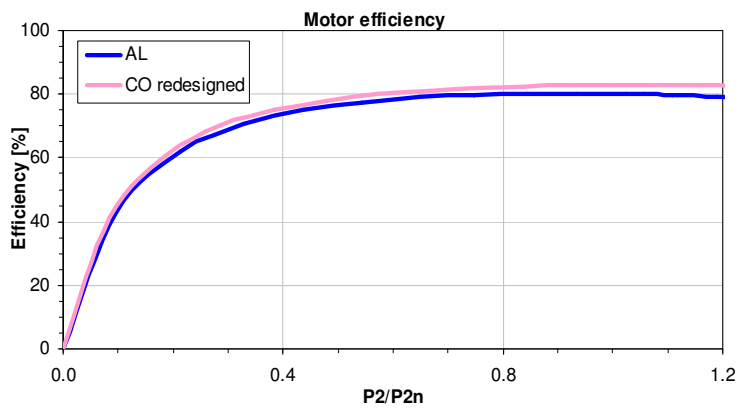

Fig. 15. Efficiency versus per unit load curve of the induction motor for aluminum cage and for redesigned copper cage.

If we take into account the interesting mechanical characteristics of the redesigned copper squirrel cage induction motor and the important energy savings that can be obtained over its typical long operation time we can draw the conclusion that the use of such machines on large scale could be a step forward in the context of the actual trend of energy efficiency and energy savings policy.

\section{Experimental validation of numerical results}

In order to validate the numerical results obtained for aluminum cage induction motor, the experimental setup presented in Fig. 16 has been used.

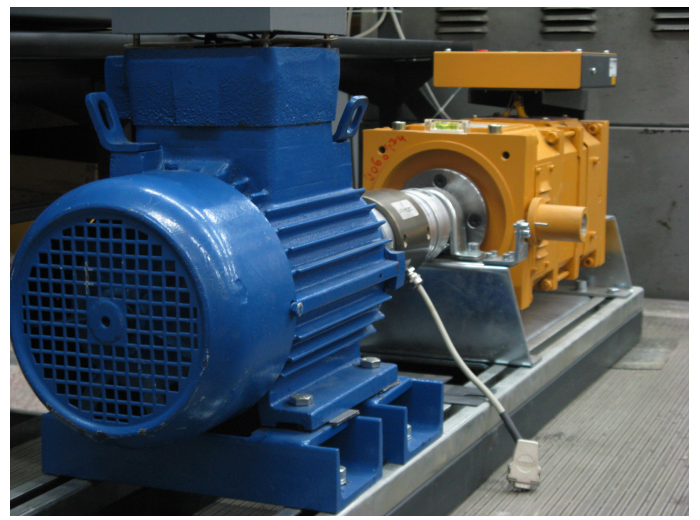

Fig. 16. Experimental setup used for experimental study of aluminum cage induction machine.

A comparison between the numerical and experimental results for aluminum cage induction motor for the rated point is presented in Table I.

TABLE I. Simulation and experimental results

\begin{tabular}{|l|c|c|c|c|}
\hline & I1 [A] & $\cos \boldsymbol{\varphi}$ & $\mathbf{M}[\mathbf{N m}]$ & Eff [\%] \\
\hline Simulation & 5.2 & 0.80 & 14.9 & 80.2 \\
\hline Experiment & 5.2 & 0.78 & 14.6 & 82.5 \\
\hline Rel. error [\%] & 0 & 2.5 & 2 & 2.8 \\
\hline
\end{tabular}

The agreement between the two sets of results is quite satisfactory, giving us confidence in the numerical results and conclusions of this study.

\section{Conclusion}

The numerical models developed in this paper referring to an induction machine working as motor and generator proved to be accurate offering useful results for a proper redesign of the machine.

The efficiency of the induction machine equipped with copper cage is superior to the efficiency of the similar machine using an aluminum cage in both cases, as motor or as generator. However a smaller starting torque obtained in case of copper cage motor with respect to the aluminum cage motor represents a first disadvantage. This drawback has been eliminated by a proper redesign of the machine. After that the starting torque of the copper cage motor becomes similar to that of the aluminum cage motor but with higher energy efficiency.

The numerical results obtained for aluminum cage induction machine were validated by experimental measurements, giving us confidence in the results and conclusions obtained for copper cage induction machine where no experiments were done so far.

\section{Acknowledgment}

This paper is a result of a research activity carried out in the frame of PNII research grants, and we take this occasion to thank the Romanian CNMP and AMCSIT projects management institutions for the support.

\section{References}

[1] CEI 60034-30 Standard, Rotating electrical machines - Part 30: Efficiency classes of single-speed, threephase, cage-induction motors (IE-code), ICS 29.160, ISBN 2-8318-1013-0, Edition 1.0 2008.

[2] Stanciu V.M., Cistelecan M., Nițiguş V., Popescu M., Politics for the use of electric machines with high electric efficiency, Electrical Engineering, Electronics and Automation, vol. 53, no. 3, 2005, Romania.

[3] Tudorache, L., Melcescu, S. Paturca, Finite Element Analysis of Self-Excited Induction Generator for Isolated Small Power Wind Turbines, ICCEP Conference 2007, Capri, Italy, 2007.

[4] Koo D.H., Han P.W., Chun Y.D., Design of Copper Rotor Induction Motor and Economical Comparison With Aluminum, Paper 247, ISEF-2007, Prague, Czech Republic, Sept, 2007.

[5] J. L. Kirtley Jr., Designing Squirrel Cage Rotor Slots with High Conductivity, Proc. of ICEM'04 Conference, Sept. 2004.

[6] Cioc I., Nica C., Design of Electrical Machines (in Romanian), EDP, Bucharest, 1994.

[7] CEI 60034-2-1 Standard, Rotating electrical machines-Part 2-1. Standard methods for determining losses and efficiency from tests, ICS 29.160, ISBN 28318-9250-3, Edition 1.02007. 